Case Report

\title{
Orbital malignant schwannoma and embryonal rhabdomyosarcoma in rats caused by leakage of locally injected nickel subsulfide to the orbit
}

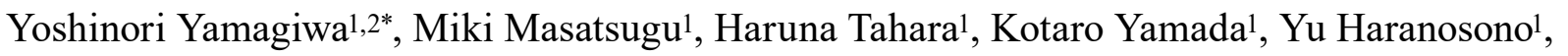 \\ Masaaki Kurata1, and Hiroshi Satoh2* \\ ${ }^{1}$ Central Research Laboratories, Senju Pharmaceutical Co., Ltd., 6-4-3 Minatojima-minamimachi, Chuo-ku, Kobe, Hyogo 650-0047, \\ Japan \\ 2 Veterinary Pharmacology and Toxicology Laboratory, Graduate School of Veterinary Sciences, Iwate University, 3-18-8 Ueda, \\ Morioka, Iwate 020-0066, Japan
}

\begin{abstract}
Nickel subsulfide $\left(\mathrm{Ni}_{3} \mathrm{~S}_{2}\right)$ is known to induce intraocular neoplasms when injected intravitreally into the eyes of rats. Here, we found two extraocular orbital neoplasms in two different rat strains, presumably due to the leakage of locally injected $\mathrm{Ni}_{3} \mathrm{~S}_{2}$ to the extraocular orbital tissues. In the $\mathrm{F} 344 / \mathrm{DuCrlCrlj}$ rat, an orbital mass arose at 30 weeks after injection, and invaded into the cranium. Histologically, the orbital mass was composed of areas arranged in parallel bundles formed by densely packed elongated or spindleshaped cells with indistinct cytoplasmic borders, and of areas of hypocellular arrangement consisting of round cells in eosinophilic myxoid-like substances. Metastases were observed in the right submandibular and cervical lymph nodes. The neoplastic cells were immunopositive for S-100 protein and vimentin. Transmission electron microscopy revealed that the neoplastic cells had cellular processes and pericytoplasmic basal laminae. In the RccHan ${ }^{\mathrm{TM}}$ :WIST rat, an orbital mass arose at 36 weeks after injection. Histologically, the mass consisted of rhabdoid-like large round cells with proliferation of small round-to-polygonal cells, and these neoplastic cells infiltrated into the extraocular muscles. Immunohistochemically, the neoplastic cells were positive for desmin and vimentin. Transmission electron microscopy detected immature myofibrils with Z-band structures in the cytoplasm of these neoplastic cells. Consequently, the tumors were diagnosed as an orbital malignant schwannoma in an F344/DuCrlCrlj rat and an orbital embryonal rhabdomyosarcoma in a RccHan ${ }^{\mathrm{TM}}$ :WIST rat. The results of this case report suggest that leakage of $\mathrm{Ni}_{3} \mathrm{~S}_{2}$ to the orbit caused the induction of orbital malignant schwannoma or rhabdomyosarcoma in rats. (DOI: 10.1293/tox.2020-0079; J Toxicol Pathol 2021; 34: 151-156)
\end{abstract}

Key words: nickel subsulfide, orbital neoplasm, malignant schwannoma, rhabdomyosarcoma, rat

Intravitreal injection of nickel subsulfide $\left(\mathrm{Ni}_{3} \mathrm{~S}_{2}\right)$ is known to induce intraocular neoplasms in Fischer rats 1 . Although several spontaneous orbital neoplasms have been reported in rats ${ }^{2-6}$, to the best of our knowledge, chemicalinduced orbital neoplasms have not been reported to date. Here, we found orbital neoplasms in F344/DuCrlCrlj (F344) and RccHan ${ }^{\mathrm{TM}}$ :WIST (Wistar Han) rats, presumably caused by the leakage of locally injected $\mathrm{Ni}_{3} \mathrm{~S}_{2}$ to the extraocular orbital tissues. In this report, we characterized their histopathological features of two orbital neoplasms in rats.

The F344 (hereafter Case 1) and Wistar Han (hereafter Case 2) rats received a single intravitreal injection of $\mathrm{Ni}_{3} \mathrm{~S}_{2}$

Received: 9 November 2020, Accepted: 2 February 2021

Published online in J-STAGE: 27 February 2021

*Corresponding authors: Y Yamagiwa

(e-mail: y-yamagiwa@senju.co.jp)

H Satoh (e-mail: satohsss@iwate-u.ac.jp)

(C2021 The Japanese Society of Toxicologic Pathology

This is an open-access article distributed under the terms of the Creative Commons Attribution Non-Commercial No Derivatives cC) $($ (by-nc-nd) License. (CC-BY-NC-ND 4.0: https:// CC ${ }_{\mathrm{BY}} \mathrm{NC}_{\mathrm{ND}}$ creativecommons.org/licenses/by-nc-nd/4.0/)
(Sigma-Aldrich, St. Louis, MO, USA) at 5 weeks of age to investigate ocular carcinogenesis. Prior to injection, $\mathrm{Ni}_{3} \mathrm{~S}_{2}$ was suspended in physiological saline (Otsuka Pharmaceutical Factory, Inc., Tokushima, Japan) at a concentration of $50 \mathrm{mg} / \mathrm{mL}$. Ten microliters of the $\mathrm{Ni}_{3} \mathrm{~S}_{2}$ suspension was aspirated into a $50 \mu \mathrm{L}$ Hamilton ultraprecise microsyringe (Hamilton Company, Reno, NV, USA) under continuous agitation with a magnetic stirrer, followed by immediate injection into the vitreous of the right eyes of 10 F344 and 14 Wistar Han rats at a dose of $0.5 \mathrm{mg}$ /eye using a $30 \mathrm{G}$ needle (Dentronics, Tokyo, Japan). Despite this dosing procedure, the concentration of $\mathrm{Ni}_{3} \mathrm{~S}_{2}$ could not be precisely controlled because $\mathrm{Ni}_{3} \mathrm{~S}_{2}$ particles partially sedimented within the microsyringe lumen during administration. The rats were housed in plastic cages at a controlled temperature of $23 \pm 3^{\circ} \mathrm{C}$ and relative humidity of $55 \pm 10 \%$ under a 12-h/12-h light/dark cycle in conventional animal rooms. All animals were given a commercial diet, Labo MR Stock (Nosan Corporation, Kanagawa, Japan), and tap water ad libitum. All experimental procedures were conducted in compliance with the guidelines for animal welfare at Senju Pharmaceutical Co., Ltd. The study adhered to the Associa- 
tion for Research in Vision and Ophthalmology statement for the Use of Animals in Ophthalmic and Vision Research. The study protocol was reviewed and approved by the Institutional Animal Care and Use Committee. Ophthalmological examinations that included anterior ocular observation and fundus observation were performed prior to dosing, one week after the treatment, and once per month thereafter using a slit-lamp biomicroscope, SL-17 (Kowa Company Ltd., Tokyo, Japan) and a binocular indirect ophthalmoscope, IO- $\alpha$ (Neitz Instruments Co., Ltd., Tokyo, Japan). When excessive abnormalities were observed around the eyes in rats of either Cases, the animals were euthanized by exsanguination via the abdominal aorta under inhalation anesthesia of sevoflurane (Mylan Inc., Canonsburg, PA, USA). Following euthanasia, the detected orbital masses were enucleated and immersed in $10 \%(\mathrm{v} / \mathrm{v})$ neutral-buffered formalin (FUJIFILM Wako Pure Chemical Corporation, Osaka, Japan) for fixing. In Case 1, the skull, brain, right cranial nerve, and swollen right submandibular and cervical lymph nodes were also collected. The skull was decalcified in 5\% formic acid/formalin solution for seven days before sectioning. After fixation, the tissues were embedded in paraffin, and sagittal sections of approximately $3 \mu \mathrm{m}$ thickness were prepared and stained with hematoxylin and eosin (HE). In Case 2, phosphotungstic acid-hematoxylin (PTAH) staining was also performed. Tissue sections of the orbital masses were stained with S-100 protein 4B3 (mouse monoclonal, ab14849, Abcam Plc., Cambridge, UK), $\alpha$-smooth muscle actin 1A4 ( $\alpha$-SMA, mouse monoclonal, ab7817, Abcam Plc.), neuron-specific enolase (NSE, rabbit polyclonal, ab53025, Abcam Plc.), vimentin V9 (mouse monoclonal, V6630, Sigma-Aldrich), desmin D33 (mouse monoclonal, 413651, Nichirei Biosciences Inc., Tokyo, Japan, only for Case 2), pan-cytokeratin AE1+AE3 (CK, NBP2-29429, Novus biologicals LLC, Centennial, CO, USA) and Melan-A M2-9E3 (mouse monoclonal, ab187369, Abcam Plc.). The immunohistochemical sections were counterstained with Mayer's hematoxylin solution (FUJIFILM Wako Pure Chemical Corporation). For transmission electron microscopy, a segment of each orbital mass was collected and fixed with $2.5 \%$ (v/v) glutaraldehyde in $0.1 \mathrm{M}$ phosphate buffer. The samples were then rinsed several times with $3 \%(\mathrm{w} / \mathrm{v})$ sucrose in 0.1 $\mathrm{M}$ phosphate buffer and postfixed with $1 \%(\mathrm{w} / \mathrm{v})$ osmium tetroxide. Following fixation, the tissues were embedded in epoxy resin, ultrathin-sectioned, and double-stained with lead citrate and uranyl acetate. The sections were examined under H-300 transmission electron microscope (Hitachi Ltd., Tokyo, Japan).

In Case 1, the ophthalmological examination detected exophthalmos and projection around the palpebral fissure in the $\mathrm{Ni}_{3} \mathrm{~S}_{2}$-treated (right) eye at 30 weeks after the treatment. In addition, dryness, dark-red deposits on the ocular surface, loss of lighting reflex, incomplete mydriasis, narrowing of iridal vessel, and diffuse lens opacity were also observed. However, owing to lens opacity, fundus could not be observed. Case 1 animal was euthanized and necropsied at 31 weeks after the treatment due to excessive pro- jection around the palpebral fissure. Necropsy examination revealed that the right orbit was filled with a milky-white mass, following which the right eyeball was extruded. The mass was observed in the cranial cavity as well, wherein the adjacent right trigeminal nerve was found swollen (Fig. 1A). Right submandibular and cervical lymph nodes were also swollen. Further, histopathological examination revealed that the orbital mass was composed of neoplastic cells, that were filling the orbital cavity and had destroyed the original orbital structure. The neoplastic cells infiltrated into the conjunctiva and eyelid (Fig. 1B) or invaded into the cranium by destroying the orbital bone tissue (Fig. 1C). Boundary of the mass was not clearly demarcated. The orbital mass was composed of areas arranged in parallel bundles formed by densely packed elongated or spindle-shaped cells with indistinct cytoplasmic borders (Antoni type A) (Fig. 1D), and of areas of hypocellular arrangement consisting of round cells in abundant eosinophilic myxoid-like substances (Antoni type B) (Fig. 1E). Mitotic figures were rare in both the areas. In the right submandibular lymph nodes, the sinus was filled with spindle-shaped neoplastic cells and the lymph node was swollen (Fig. 1F). The neoplastic cells had round-to-oval nuclei, and proliferated with the intercellular fibrous structure. Based on these characteristics, the lesions in the lymph nodes were identified as orbital metastases. In the immunohistochemical examination, the neoplastic cells were found positive for S-100 protein (Fig. 1G) and vimentin (Fig. 1H), and negative for CK, $\alpha$-SMA, Melan-A, and NSE in the both the areas. Transmission electron microscopy showed oval-to-rod-shaped nuclei in the neoplastic cells. Further, these cells contained cytoplasmic organelles, including mitochondria, free ribosomes, and occasionally expanded endoplasmic reticulum. Notably, some cells had long or short cellular processes (Fig. 1I). The electron-dense basal laminae were sparsely distributed in the pericytoplasmic region of the neoplastic cells (Fig. 1J). Occasionally, fibrous structures were observed in the intercellular spaces. The orbital mass consisted of proliferative neoplastic cells showing invasive growth to the surrounding tissues. In addition, regional lymph node metastases were observed, indicating that the mass was indeed a malignant neoplasm. Considering these histopathological, immunohistochemical, and ultrastructural findings, the orbital mass was diagnosed as an orbital malignant schwannoma with right submandibular and cervical lymph node metastases. Case 1 animals exhibited characteristic cellular arrangements, such as presence of Antoni type A and B, cellular processes, and pericytoplasmic basal laminae, along with the neoplastic cells testing positive for S-100 protein and vimentin. Unfortunately, the origin of the neoplasm could not be determined since most of the orbital tissues were destroyed by the proliferative neoplastic cells. However, the nerve fibers, such as ophthalmic or ciliary nerves, were distributed in the orbit, suggesting that the tumor was presumably from the nerve sheath.

In Case 2, a right orbital mass was first found at 36 weeks after the treatment. Prior to the appearance of this 

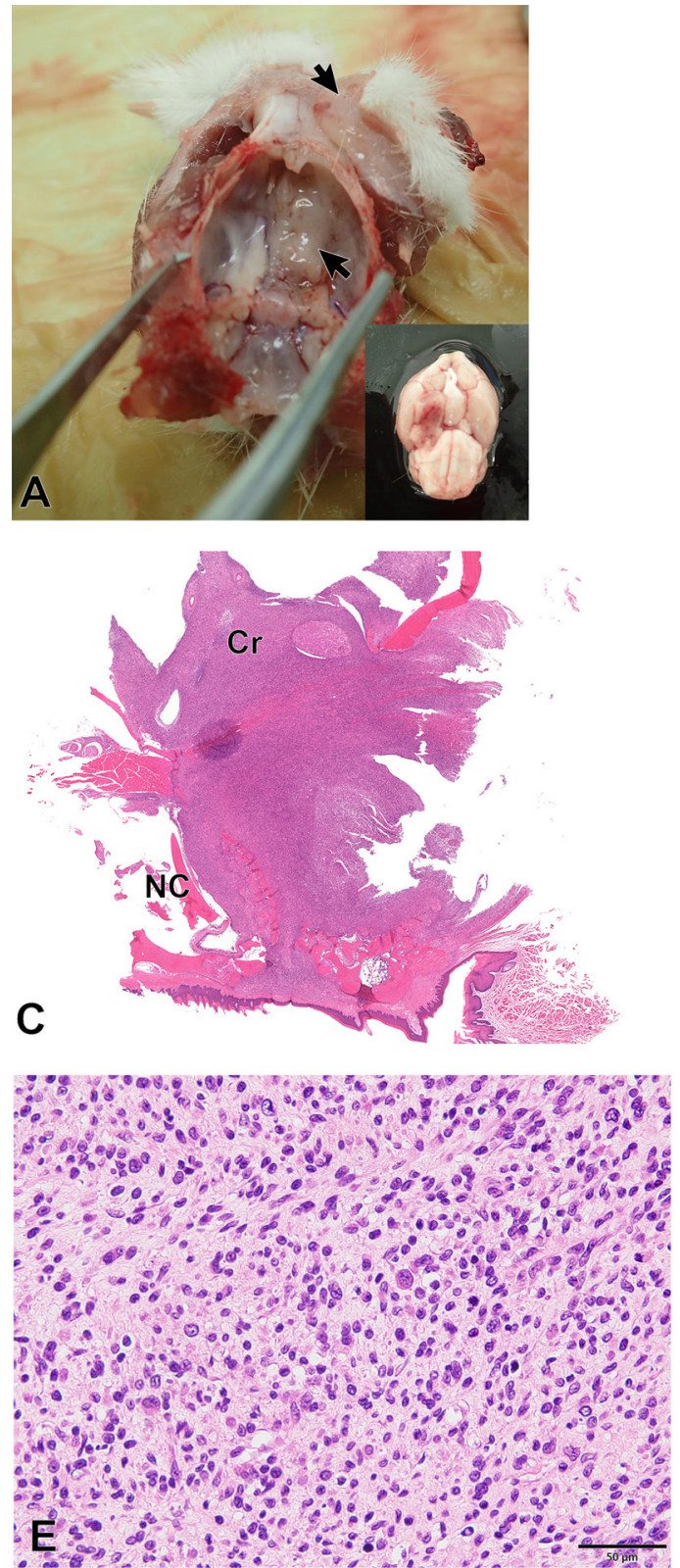

Fig. 1.

orbital mass, vitreal linear structure, and crystalline materials were observed from 22 weeks after the treatment. The animal was euthanized and necropsied at 37 weeks after the treatment owing to excessive enlargement of the right orbital mass. Necropsy examination revealed an ivory-to-grayish-colored mass filled in the right orbit, following which the right eyeball was extruded. Histopathological examination revealed that the mass consisted of proliferative neoplastic cells with some necrotic foci, and destroyed original orbital tissues (Fig. 2A). The neoplastic cells infiltrated into the extraocular muscles, and the muscle fibers were atrophied (Fig. 2B). In addition, the neoplastic cells infiltrated into the right eyeball. It was found that the neoplastic cells were composed of plump rhabdoid-like large round cells and relatively small round-to-polygonal cells (Fig. 2C). In
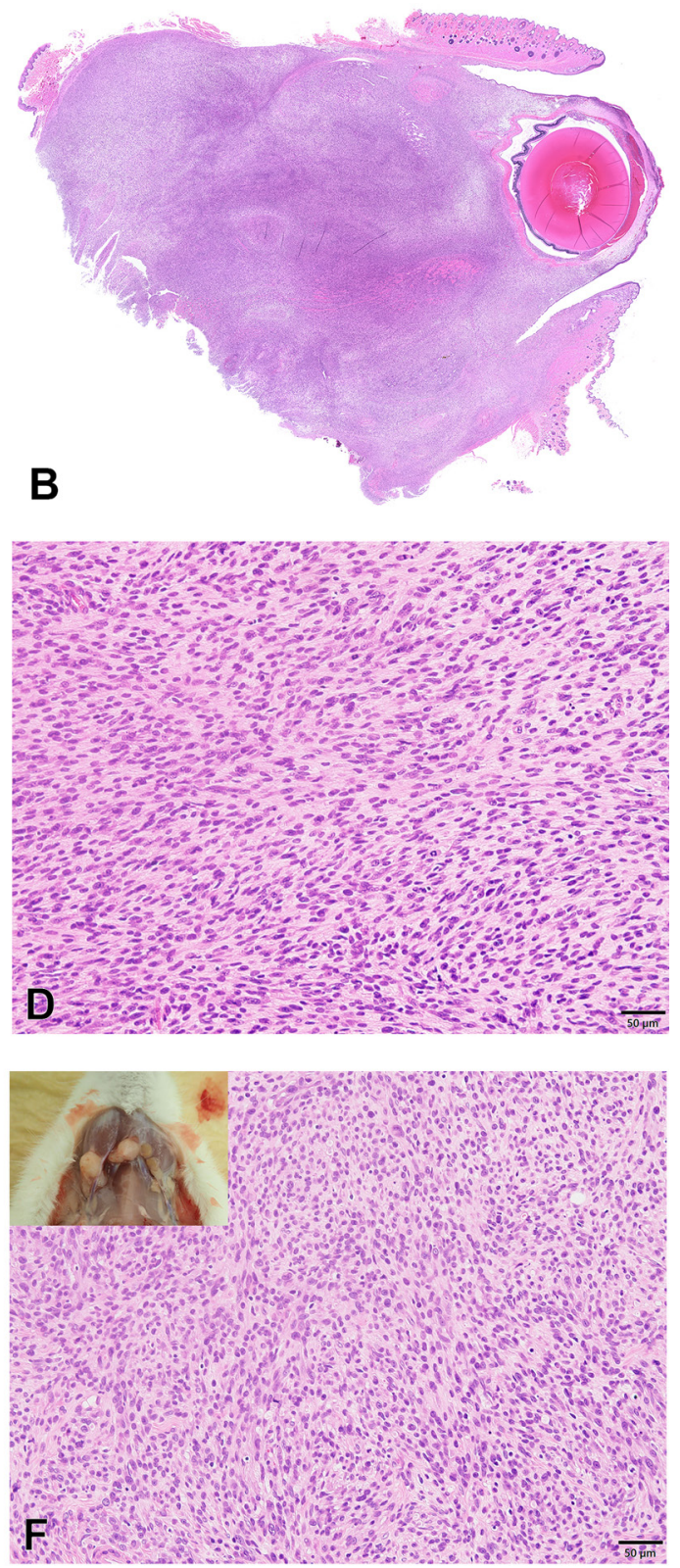

higher magnification, the plump rhabdoid-like cells had one or a few round nuclei with a prominent pale or fibrillary eosinophilic cytoplasm. The proliferated round-to-polygonal cells had one nucleus with poor cytoplasm (Fig. 2D). Mitotic figures were occasionally observed. The neoplastic cells had no clear striations in the cytoplasm even in the PTAHstained section. Immunohistochemistry showed that the neoplastic cells were strongly positive for desmin (Fig. 2E), weakly positive for vimentin (Fig. $2 \mathrm{~F}$ ), and negative for CK, $\alpha$-SMA, Melan-A, NSE, and S-100 protein. In the transmission electron microscopy, the rhabdoid-like large round cells were identified as plump rhabdomyoblast-like cells that had one or a few round-to-elliptic nuclei with abundant cytoplasm containing organelles such as mitochondria (Fig. 2G). The small round-to-polygonal cells were recognized as rela- 

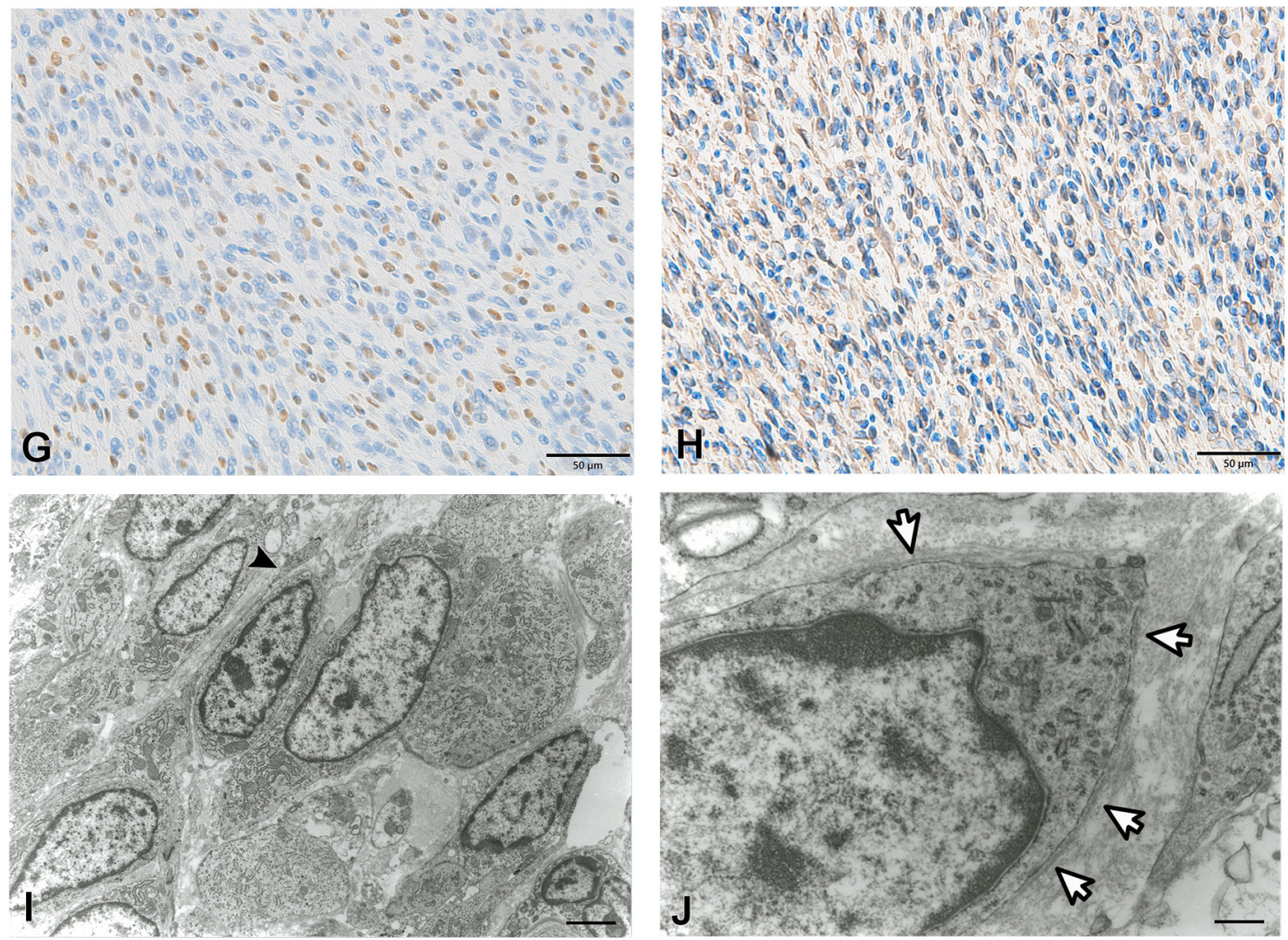

Fig. 1. Continued Case 1: An orbital malignant schwannoma in an F344 rat arising at 31 weeks after injection of nickel subsulfide to the orbit. A milky-white mass (arrows) fills the right orbit and invades the cranium (A). Right trigeminal nerve is swollen (A inset). The mass fills the orbit and the neoplastic cells infiltrate into the conjunctiva and eyelid (B), or the cranium (Cr) and nasal cavity (NC) (C). The mass is composed of areas arranged in parallel bundles formed by densely packed elongated or spindle-shaped cells with indistinct cytoplasmic borders (Antoni type A) (D), or a hypocellular arrangement consisting of round cells in eosinophilic myxoid-like substances (Antoni type B) (E). Right submandibular lymph nodes are filled with the spindle-shaped neoplastic cells (F) and are grossly swollen (F inset). The neoplastic cells are positive for S-100 protein $(\mathrm{G})$ and vimentin $(\mathrm{H})$. Transmission electron micrographs show that the neoplastic cells have cellular processes (arrowhead) (I), or electron-dense pericytoplasmic basal laminae (open arrows) (J). HE staining (B-F), immunohistochemical staining of S-100 protein $(\mathrm{G})$ or vimentin $(\mathrm{H})$, and transmission electron micrographs $(\mathrm{I}, \mathrm{J})$. Scale bars $=50 \mu \mathrm{m}(\mathrm{D}-\mathrm{H}), 2$ $\mu \mathrm{m}(\mathrm{I})$, and $400 \mathrm{~nm}(\mathrm{~J})$.

tively small rhabdomyoblast-like cells. The plump rhabdomyoblast-like cells had randomly arranged immature myofibrils with Z-band structures in the cytoplasm (Fig. 2H). The mass was composed of proliferative neoplastic cells that showed cellular pleomorphism, and invasive growth to the extraocular muscles and the other orbital tissues, indicating that the mass was indeed a malignant neoplasm. Even though no clear striations were observed in the PTAHstained section, the neoplastic rhabdoid-like cells were immunopositive for desmin and vimentin, and had Z-band structures in the cytoplasm, as detected by transmission electron microscopy. In addition, the neoplasm contained a large number of small, undifferentiated round-to-polygonal cells with proliferation of rhabdoid-like large round cells, which is a typical embryonal variant. Based on these histological, immunohistochemical, and ultrastructural findings, the mass was diagnosed as an orbital embryonal rhabdomyosarcoma. The neoplastic cells intensively infiltrated into the skeletal muscle fibers in the orbit, suggesting that the neoplasm originated from the extraocular muscles.
No orbital neoplasms were observed in the other animals treated with intravitreal injection of $\mathrm{Ni}_{3} \mathrm{~S}_{2}$. Intraocular neoplasms were induced in other two Wistar Han rats.

Generally, spontaneous orbital/intracranial neoplasms are rare in rats of such young age. Incidences of orbital neoplastic changes in either Wistar Han or F344 rats including young ones have not been recorded in recent historical control data of several test facilities ${ }^{7-12}$. Similarly, no early spontaneous orbital/intracranial neoplasm in Sprague-Dawley rats has been recorded in recent historical control data ${ }^{13,14}$. However, in aged F344 rats, spontaneous intraocular and orbital schwannomas have been reported 5 . Some case reports in Sprague-Dawley rats have described orbital amelanotic melanoma in a 67 -week-old animal ${ }^{6}$ and trigeminal nervederived intracranial schwannomas in 19- and 28-week-old animals ${ }^{15}, 16$. To the best of our knowledge, orbital rhabdomyosarcoma has not been previously reported as spontaneous neoplasm in rats. The neoplastic changes did not arise in the orbit in the untreated left eyes in this study. These facts suggest that the two extraocular orbital neoplasms were 

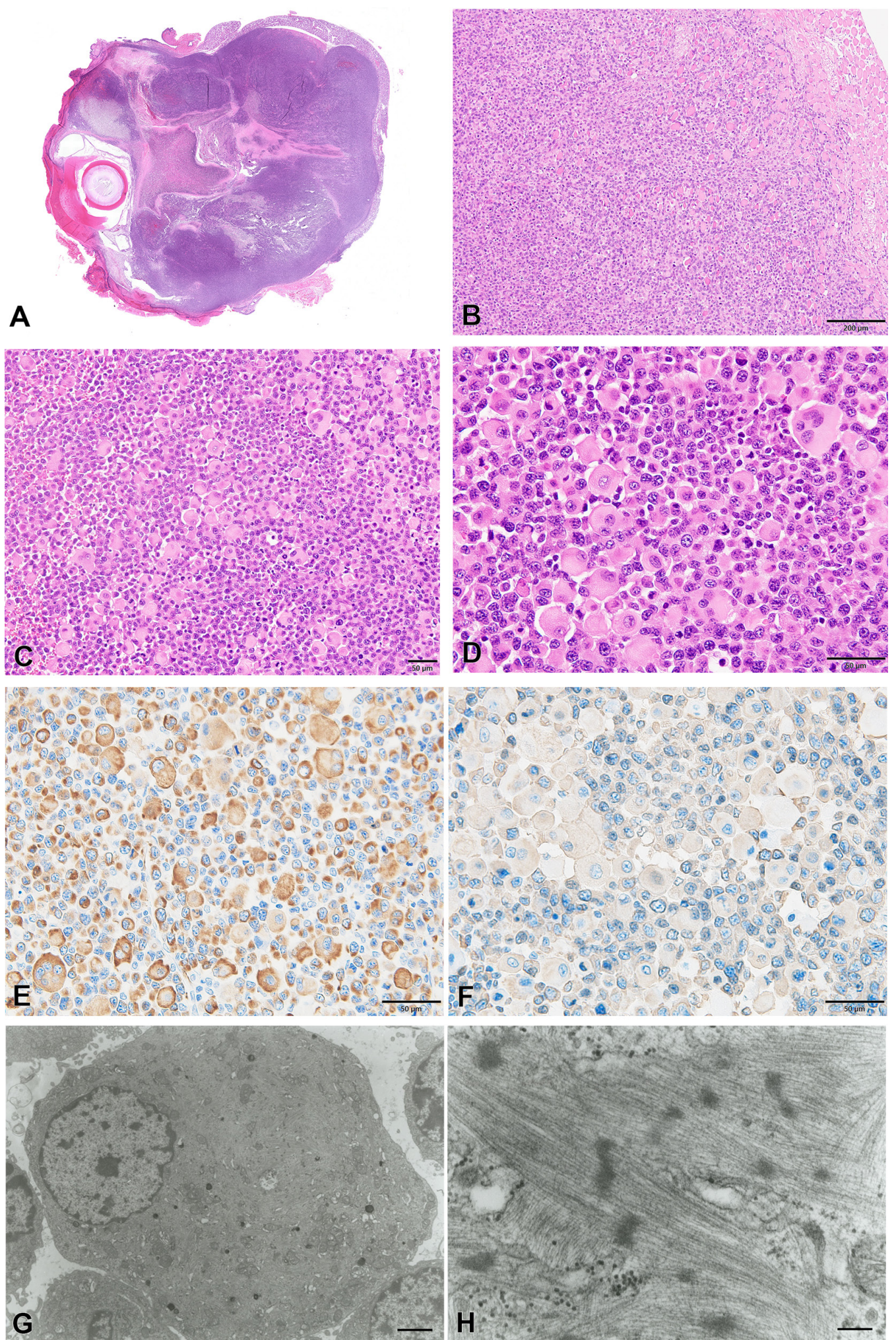

Fig. 2. Case 2: An orbital embryonal rhabdomyosarcoma in a Wistar Han rat arising at 37 weeks after injection of nickel subsulfide to the orbit. A mass is located behind the eye, and some necrotic areas can be observed (A). The neoplastic cells infiltrate into the extraocular muscles (B). The mass consists of rhabdoid-like large round cells with proliferation of small round-to-polygonal cells (C). The rhabdoid-like cells have one or a few round nuclei with prominent pale or fibrillary eosinophilic cytoplasm, and the round-to-polygonal cells have one nucleus with relatively poor cytoplasm (D). The rhabdoid-like cells are strongly positive for desmin (E) and weakly positive for vimentin (F). Transmission electron microscopy identities the rhabdoid-like large round cells as plump rhabdomyoblast-like neoplastic cells (G) that contain immature myofibrils with Z-band structures in the cytoplasm (H). HE staining (A-D), immunohistochemical staining of desmin $(E)$ or vimentin $(F)$, and transmission electron micrographs (G, H). Scale bars $=200 \mu \mathrm{m}(\mathrm{B}), 50 \mu \mathrm{m}(\mathrm{C}-\mathrm{F}), 2 \mu \mathrm{m}(\mathrm{G})$, and $200 \mathrm{~nm}$ $(\mathrm{H})$. 
treatment-related, and not spontaneous lesions.

In a previous study, intravitreal injection of $\mathrm{Ni}_{3} \mathrm{~S}_{2}$ in F344 rats induced intraocular neoplasms including retinoblastoma, glioma, and melanoma ${ }^{1}$. However, extraocular orbital neoplasms were not described then. By administering $\mathrm{Ni}_{3} \mathrm{~S}_{2}$ to $\mathrm{F} 344$ rats via several dosing routes, the neoplasms arose around the areas of administration sites ${ }^{17,18}$. Intramuscular injection of $\mathrm{Ni}_{3} \mathrm{~S}_{2}$ is known to induce rhabdomyosarcoma in F344 or Wistar rats ${ }^{19-21}$. These results suggest that $\mathrm{Ni}_{3} \mathrm{~S}_{2}$ poses carcinogenic potential when in contact with the tissues of these animals. In the present study, a possible cause of induction of orbital neoplastic changes is that $\mathrm{Ni}_{3} \mathrm{~S}_{2}$ leaked into the extraocular orbital tissues following accidental injection by perforation of needles and affected the orbital Schwann cells or the skeletal muscles. The results of this case report suggest that leakage of locally injected $\mathrm{Ni}_{3} \mathrm{~S}_{2}$ to the orbit underlies the induction of orbital malignant schwannoma or rhabdomyosarcoma in rats.

Disclosure of Potential Conflicts of Interest: The authors declare no potential conflicts of interest with respect to the research, authorship, and/or publication of this article.

Acknowledgments: The authors thank Mr. Yoshihiro Takei and the staff of Ina Research Inc. for their help in preparing the specimens for histopathological and ultrastructural examination. Their dedication and excellent efforts made these investigations possible.

\section{References}

1. Albert DM, Gonder JR, Papale J, Craft JL, Dohlman HG, Reid MC, and Sunderman FW Jr. Induction of ocular neoplasms in Fischer rats by intraocular injection of nickel subsulfide. Invest Ophthalmol Vis Sci. 22: 768-782. 1982. [Medline]

2. Ackerman LJ, Yoshitomi K, Fix AS, and Render JA. Proliferative lesions of the eye in rats, OSS. In: Guides for Toxicologic Pathology. STP/ARP/AFIP, Washington, DC. 1-14. 1998.

3. Dunn DG, Baker JFM, and Sorden SD. Eye and associated glands. In: Boorman's Pathology of the Rat, Reference and Altras, 2nd ed. AW Suttie, JR Leininger, and AE Bradley (eds). Academic Press, New York. 251-278. 2018.

4. Yoshitomi K, and Boorman GA. Eye and associated glands. In: Pathology of the Fischer Rat, Reference and Atlas. GA Boorman, SL Eustis, MR Elwell, CA Montgomery Jr, and WF MacKenzie (eds). Academic Press, New York. 239-259. 1990.

5. Yoshitomi K, and Boorman GA. Intraocular and orbital malignant schwannomas in F344 rats. Vet Pathol. 28: 457-466. 1991. [Medline] [CrossRef]

6. Kurotaki T, Tomonari Y, Kanno T, Wako Y, and Tsuchitani M. Malignant amelanotic melanoma behind the left eye in a female Crj:CD(SD)IGS rat: a case report. Vet Pathol. 45: 681-684. 2008. [Medline] [CrossRef]

7. Hojo M, Sakamoto Y, Maeno A, Tayama K, Tada Y, Yuzawa K, Ando H, Kubo Y, Nagasawa A, Tanaka K, Yano N, Kaihoko F, Hasegawa Y, Suzuki T, Inomata A, Moriyasu T, Miyajima K, and Nakae D. A histopathological analysis of spontaneous neoplastic and non-neoplastic lesions in aged male RccHan:WIST rats. J Toxicol Pathol. 33: 47-55. 2020. [Medline] [CrossRef]

8. Kuroiwa Y, Ando R, Kasahara K, Nagatani M, Yamakawa $\mathrm{S}$, and Okazaki S. Transition of historical control data for high incidence tumors in $\mathrm{f} 344$ rats. J Toxicol Pathol. 26: 227-230. 2013. [Medline] [CrossRef]

9. Iwata H, Hirouchi Y, Koike Y, Yamakawa S, Kobayashi K, Yamamoto T, Kobayashi K, Inoue H, and Enomoto M. Historical control data of nonneoplastic and neoplastic lesions in F344/DuCrj rats. J Toxicol Pathol. 4: 1-24. 1991. [CrossRef]

10. Hayakawa K, Mimura Y, Tachibana S, Furuya M, Kodama T, Aoki T, Hosokawa S, Fukui M, Shibata S, Yoshida M, Masuyama T, Narita T, Kuwagata M, Hisada S, and Maki E. Study for collecting background data on Wistar Hannover [Crl:WI(Han)] rats in general toxicity studies--comparative data to Sprague Dawley rats. J Toxicol Sci. 38: 855-873. 2013. [Medline] [CrossRef]

11. Okamura T, Suzuki S, Ogawa T, Kobayashi J, Kusuoka O, Hatayama K, Mochizuki M, Hoshiya T, Okazaki S, and Tamura K. Background data for general toxicology parameters in RccHan:WIST rats at 8, 10, 19 and 32 weeks of age. J Toxicol Pathol. 24: 195-205. 2011. [Medline] [CrossRef]

12. Son WC, Bell D, Taylor I, and Mowat V. Profile of early occurring spontaneous tumors in Han Wistar rats. Toxicol Pathol. 38: 292-296. 2010. [Medline] [CrossRef]

13. Son WC, and Gopinath C. Early occurrence of spontaneous tumors in CD-1 mice and Sprague-Dawley rats. Toxicol Pathol. 32: 371-374. 2004. [Medline] [CrossRef]

14. Ikezaki S, Takagi M, and Tamura K. Natural occurrence of neoplastic lesions in young sprague-dawley rats. J Toxicol Pathol. 24: 37-40. 2011. [Medline] [CrossRef]

15. Yoshizawa K, Oishi Y, Makino N, Suzuki J, Matsumoto M, Yamauchi K, Fujihira S, and Fujii T. Malignant schwannoma of the intracranial trigeminal nerve in a 19-week-old female Sprague-Dawley rat. J Toxicol Pathol. 9: 107-112. 1996. [CrossRef]

16. Nagatani M, Yamakawa S, Ando R, Edamoto H, Saito T, and Tamura K. Highly invasive intracranial malignant schwannoma in a rat. J Toxicol Pathol. 22: 139-142. 2009. [Medline] [CrossRef]

17. Shibata M, Izumi K, Sano N, Akagi A, and Otsuka H. Induction of soft tissue tumours in F344 rats by subcutaneous, intramuscular, intra-articular, and retroperitoneal injection of nickel sulphide $\left(\mathrm{Ni}_{3} \mathrm{~S}_{2}\right)$. J Pathol. 157: 263-274. 1989. [Medline] [CrossRef]

18. Sunderman Jr FW. Recent research on nickel carcinogenesis. Environ Health Perspect. 40: 131-141. 1981. [Medline] [CrossRef]

19. Yamashiro S, Gilman JPW, Basrur PK, and Abandowitz HM. Growth and cytogenetic characteristics of nickel sulphide-induced rhabdomyosarcomas in rats. Acta Pathol Jpn. 28: 435-444. 1978. [Medline]

20. Yamashiro S, Basrur PK, Gilman JPW, Hulland TJ, and Fujimoto Y. Ultrastructural study of $\mathrm{Ni}_{3} \mathrm{~S}_{2}$-induced tumors in rats. Acta Pathol Jpn. 33: 45-58. 1983. [Medline]

21. Hildebrand HF, and Biserte G. Ultrastructural investigation of $\mathrm{NI}_{3} \mathrm{~S}_{2}$-induced rhabdomyosarcoma in Wistar rat: comparative study with emphasis on myofibrillar differentiation and ciliar formation. Cancer. 42: 528-554. 1978. [Medline] [CrossRef] 